PREPARED FOR THE U.S. DEPARTMENT OF ENERGY, UNDER CONTRACT DE-AC02-76CH03073

PPPL-3736

PPPL-3736

UC-70

Simulations of Temperatures in Burning Tokamak Plasmas Using the GLF23 Model in the TRANSP Code

by

R.V. Budny

August 2002

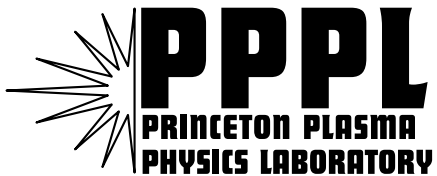

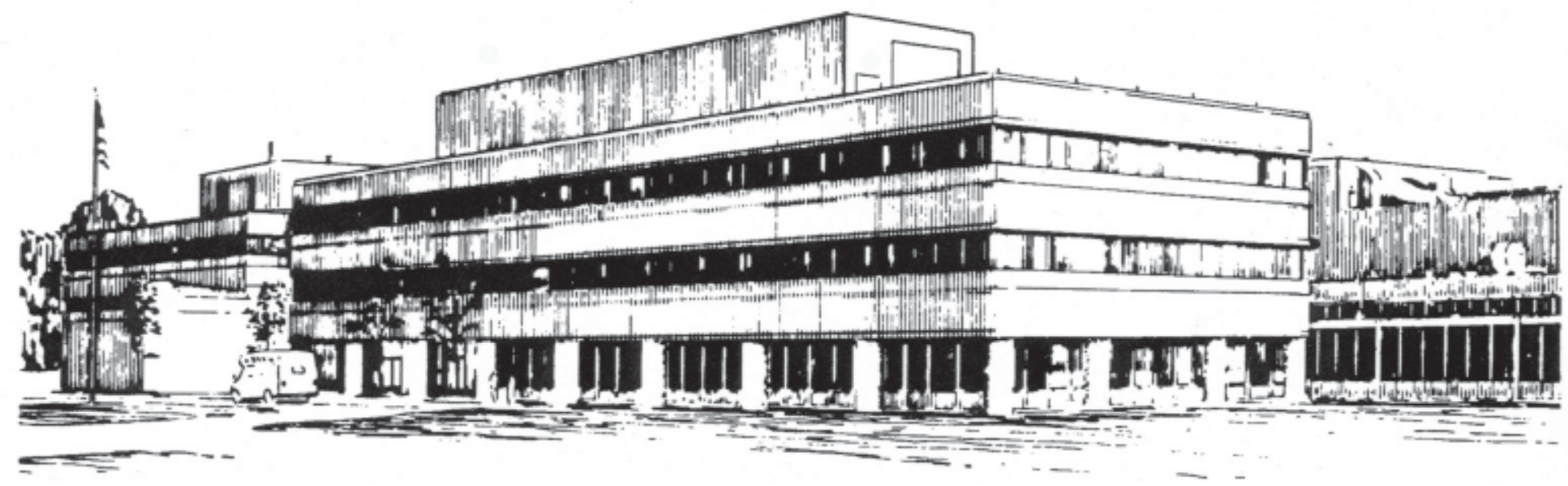

PRINCETON PLASMA PHYSICS LABORATORY PRINCETON UNIVERSITY, PRINCETON, NEW JERSEY 


\section{PPPL Reports Disclaimer}

This report was prepared as an account of work sponsored by an agency of the United States Government. Neither the United States Government nor any agency thereof, nor any of their employees, makes any warranty, express or implied, or assumes any legal liability or responsibility for the accuracy, completeness, or usefulness of any information, apparatus, product, or process disclosed, or represents that its use would not infringe privately owned rights. Reference herein to any specific commercial product, process, or service by trade name, trademark, manufacturer, or otherwise, does not necessarily constitute or imply its endorsement, recommendation, or favoring by the United States Government or any agency thereof. The views and opinions of authors expressed herein do not necessarily state or reflect those of the United States Government or any agency thereof.

\section{Availability}

This report is posted on the U.S. Department of Energy's Princeton Plasma Physics Laboratory Publications and Reports web site in Fiscal Year 2002. The home page for PPPL Reports and Publications is: http://www.pppl.gov/pub_report/

DOE and DOE Contractors can obtain copies of this report from:

U.S. Department of Energy

Office of Scientific and Technical Information

DOE Technical Information Services (DTIS)

P.O. Box 62

Oak Ridge, TN 37831

Telephone: (865) 576-8401

Fax: (865) 576-5728

Email: reports@adonis.osti.gov

This report is available to the general public from:

National Technical Information Service

U.S. Department of Commerce

5285 Port Royal Road

Springfield, VA 22161

Telephone: 1-800-553-6847 or

(703) 605-6000

Fax: (703) 321-8547

Internet: http://www.ntis.gov/ordering.htm 


\title{
Simulations of temperatures in burning Tokamak plasmas using the GLF23 model in the TRANSP code
}

\author{
R.V. Budny ${ }^{1}$ \\ PPPL, Princeton University, P.O. Box 451, Princeton, NJ 08543, USA
}

(29-Jul-2002)

The GLF23 prediction model, incorporated in the TRANSP plasma analysis code, is used to predict temperatures for burning plasmas in the proposed FIRE and ITER-FEAT Tokamaks. Flat electron density profiles with various central values are assumed. Scaling of the fusion power $P_{d t}$ and gain $Q_{d t}$ with density and pedestal temperature are given. Helium ash transport and sawtooth effect $P_{d t}$ in long duration ITER-FEAT plasmas. Classification: MO (Reactor Physics and Design)

\section{Introduction}

Nest-step tokamaks for burning plasma experiments are being proposed. In order for these experiments to provide clear results for alpha heating studies and for reliable extrapolations to fusion power reactors, the $\mathbf{d t}$ fusion power $P_{d t}$ and fusion gain $Q_{d t}=P_{d t} / P_{a u x}$ should be large. Two of the proposed next-step tokamaks, FIRE [1] and ITER-FEAT [2] have the goal of achieving $Q_{d t}=$ 10. The plasma durations are projected to about 20 and $400 \mathrm{~s}$, respectively.

There are many uncertainties in extrapolating present tokamak experiments to those envisioned in burning Tokamak plasmas. One of the theory-based predictive models, GLF23 [3], is promising since it has been successful in simulating $T_{e}$ and $T_{i}$ in present plasmas. This model has been incorporated into the TRANSP plasma analysis code [4], which has strong capabilities for simulating the heat depositions in present experiments.

The goal of this paper is apply the TRANSP-GLF23 code to simulate $T_{e}, T_{i}, P_{d t}$, and $Q_{d t}$ in FIRE and ITER-FEAT plasmas. Peaked electron density profiles have been proposed for FIRE since they are often associated with high energy confinement in present experiments, but there is uncertainty as to whether they can be created in the high density and temperature plasmas required for high $Q_{d t}$. To be conservative about the technological difficulties in generating peaked density profiles, very broad $n_{e}$ profiles, similar to those envisioned for the ITER-FEAT tokamak [2], are assumed.

Other studies have used the GLF23 model to predict temperatures in FIRE and ITER-FEAT plasmas, using, for instance, the TSC [5] code. The TRANSP code uses a number of difference techniques, such as Monte Carlo techniques [6] to calculate the fusion alpha heating, and the SPRUCE full-wave, reduced order code [7] to calculate the ICRH heating. Also the accumulation of the alpha ash is computed. The results of this study for FIRE are optimistic than in that the height of the pedestal temperature needed for $Q_{d t} \geq 10$ is relatively low, around $2.5 \mathrm{keV}$. The

\footnotetext{
${ }^{1}$ email: budny@princeton.edu
} 
results for ITER-FEAT indicate that the time scale for $P_{d t}$ to increase can be very long due to the slow accumulation of the alpha ash.

\section{FIRE Plasmas.}

FIRE [1] is designed to have normal-conducting magnets, and a double-null divertor geometry. The normal heating scheme is ICRH at a frequency of $100 \mathrm{MHz}$ to resonate with small concentrations of $\mathrm{He}^{3}$ and large concentrations of $\mathbf{T}$ on axis. The heating power $P_{R F}$ is assumed to start high (20 MW) early in the discharge to provoke the $\mathrm{L}$ to $\mathrm{H}$-mode transition, and then is lowered to 11.5 MW as the alpha heating increases, to maintain the $\mathrm{H}$-mode. The assumed evolution of the heating powers are shown in Fig. 1. The ICRH heating and alpha parameters for a similar FIRE H-mode plasma are discussed in Ref. 8. Plasma parameters for a FIRE AT plasma are discussed in Ref. 9.

The toroidal field is assumed to be 10 [T], and the plasma current $I_{p}$ is ramped to a flattop value of 7.7 [MA] for 20 [s], as shown in Fig. 2. The area-integrated bootstrap current calculated from neoclassical theory [10] for one of the simulations is also shown in the Fig. The $q_{M H D}$ profile at several times is shown in Fig. 3, plotted against the toroidal flux variable, $x \equiv \sqrt{\text { normalized toroidal flux }}$, which is roughly equal to $\mathrm{r} / \mathrm{a}$. The relatively rapid ramp-up of $I_{p}$ and $T_{e}$ have the result of keeping $q_{M H D} \geq \mathbf{1 . 0}$ for most of the discharge

The central plasma densities are assumed to ramp-up as shown in Fig. 4. Plasma profiles in the flattop are shown in Fig. 5. The $Z_{e f f}$ profile is assumed to be about 1.36. Accumulation of the alpha ash is modeled, as described in Ref. 10, assuming a recycling coefficient of $20 \%$. The discharge duration is too short for the ash concentration to reach steady state, or to significantly reduce $P_{d t}$.

The TRANSP plasma analysis code is used to analyze plasmas with either measured or assumed plasma profiles. TRANSP is a fixed-boundary code, so the FIRE plasma boundary is specified by assuming time evolutions of the major and minor radii, elongation, triangularity, and vertical displacement of the boundaries. The MHD equilibria are calculated in TRANSP by solving the Grad-Shafranov equation. The heat and particle fluxes are calculated from the continuity equations. The fusion alpha particles and beam ions are treated using Monte Carlo methods [6] to model their source rates, neoclassical orbits, and slowing-down rates.

The Kadomstev sawtooth mixing model is used to helically mix the current and temperatures if $q_{M H D}(0)$ is less than unity at sawtooth breaks, assumed to occur with a period of $1 \mathrm{~s}$. Examples of results for the computed $q_{M H D}(0)$ for four simulations are shown in Fig. 6. These four are from a scan with the Greenwald ratio $f_{G W}=\bar{n}_{e} / \bar{n}_{\text {Greenwald }}$ varied. With the plasma startup assumed, only one of the plasmas has sufficient time for $q_{M H D}(0)$ to decrease below unity. The simulated plasmas with low pedestal temperature have sawteeth throughout the flattop.

An example of the evolutions of the central $T_{e}$ and $T_{i}$ for one of the plasmas are shown in Fig. 7. The GLF23 prediction starts at $5 \mathrm{~s}$. At that time, the central temperatures drop from their guessed values, then rise again with the start of the ICRH at 6 [s]. They continue to rise until about 27 [s], when the density starts to ramp down.

The predictions start from an assumed boundary temperature, nominally at the top of the H-mode pedestal. Here, this boundary is assumed to occur at $x=0.95$. The evolution of the 
assumed pedestal temperature is shown in Fig. 7. Note that it is not held fixed in time. A scan was done with the pedestal temperature held at $5.4 \mathrm{keV}$, with the density scaled. Results for the $T_{i}$ at the time of peak value is shown in Fig. 8. During this scan $f_{G W}$ varied from 0.29 to 0.66. The resulting peak values for $P_{d t}$ and $\beta_{n}$ are plotted in Fig. 9. Since the auxiliary heating power at that time is $P_{R F}+P_{O h}=11.5+1.0[\mathrm{MW}]$, the $Q_{d t}$ is greater than 10 for $\bar{n}_{e} / \bar{n}_{\text {Greenwald }} \geq \mathbf{0 . 4 0}$.

Lastly, $\bar{n}_{e} / \bar{n}_{\text {Greenwald }}$ is held fixed at 0.66 and the pedestal temperature is scanned down to 2.4 [keV]. The resulting profiles for $T_{i}$ at the peak are shown in Fig. 10. The values for $T_{e}$ are shown in Fig. 11. The values for $P_{d t}$ and $\beta_{n}$ are plotted in Fig. 12. Thus a pedestal temperature of about $2[\mathrm{keV}]$ appears sufficient to achieve $Q_{d t} \geq 10$. Results are given in Table 1.

\section{ITER-FEAT plasmas}

ITER-FEAT [2] is designed to have super-conducting magnets for long pulse duration, and a single-null divertor geometry. The plasma is assumed to be in the ELMy H-mode regime with a $n_{e}$ profile close to those in Ref. [2] with a target DT fusion yield of $P_{D T}=400$ [MW]. The $n_{e}$ profile has the same shape as the FIRE plasma (Fig. 5), with a central value ramped up to $1.02 \times 10^{20} / \mathrm{m}^{3}$ during the flattop.

The assumed ICRH and NNBI heating powers and durations are shown in Fig. 13. The NNBI injection is assumed to be in the plasma current direction at a tangency radius of $6 \mathrm{~m}$. The toroidal rotation of the thermal plasma during the NNBI is computed, assuming $\chi_{\operatorname{mom}}=\chi_{\mathrm{i}}$, to peak at $15 \mathrm{krad} / \mathrm{s}$, corresponding to a central Mach number (ratio of velocity and thermal speed) of 0.1. The ratio the central rotation and Alfvén speeds is 1.1-1.4\% during the NNBI.

Two values for the flattop temperature pedestal (at $x=0.85$ ) were used, 3.9 and $5.1 \mathrm{keV}$. Several assumptions for the helium ash transport were assumed,

$\Gamma_{a s h}=\left(-D_{a s h} \nabla n_{a s h}+V_{a s h} n_{a s h}\right) A_{\text {surf }}$,

with $A_{\text {surf }}$ the area of the flux surface at $x, D_{a s h}=0.5$ or $0.8 \mathrm{~m}^{2} / \mathrm{s}$, and $V_{a s h}=0$ or $-0.1 \mathrm{~m} / \mathrm{s}$.

After the ICRH and NNBI are stopped, $P_{d t}$ and the alpha heating continue to increase slowly, as shown in Fig. 13. The temperature profiles from two simulations with different pedestal temperatures are shown in Fig. 14. As expected for relatively stiff transport models such as GLF23, the central temperatures and $P_{d t}$ increase with pedestal temperature. The sawtooth mixing radius increases slowly as $T_{e}(0)$ increases. Sawtooth mixing reduces the alpha ash in the center, and the concentration does not reach equilibrium after $400 \mathrm{~s}$. Results are summarized in Table 2.

\section{Summary and Discussion}

This paper reports results for self-consistent transport simulations of burning plasmas for FIRE and ITER-FEAT using the GLF23 model incorporated into the TRANSP analysis code. Relatively flat density profiles are assumed for both. ICRH is assumed for both, and NNBI is assumed for ITER-FEAT. For FIRE with the assumed heating, the plasmas achieve $Q_{d t} \geq 10$ for $\bar{n}_{e} / \bar{n}_{\text {Greenwald }}=$ 0.66 with pedestal temperatures as low as $2.5[\mathrm{keV}]$. For the ITER-FEAT plasmas, the predicted central temperatures continue to increase slowly with $P_{d t}$ after the ICRH and NNBI are stopped. 
The results for $P_{d t}$ and $Q_{d t}$ depend sensitively on the pulse durations. The relatively short pulse durations in FIRE $(\simeq 20 \mathrm{~s})$ imply that the pedestal temperature is a key parameter. The relatively long ( $>300 \mathrm{~s}$ ) imply that very large $Q_{d t}$ could be anticipated, and that $P_{d t}$ will depend sensitively on details of the ash transport and on sawtooth mixing.

\section{Acknowledgments}

The author wishes to thank K. Indireshkumar, S. Jardin, and D. McCune for coding GLF23 in TRANSP. This work was supported in part by the US DoE Contract No. DE-AC02-76CH03073.

\begin{tabular}{||lccccccc||}
\hline \hline TRANSP run ID & $\bar{n}_{e} / \bar{n}_{\text {Greenwald }}$ & $\beta_{n}$ & $T_{p e d}$ & $P_{d t}$ & $P_{\alpha}$ & $\tau_{E}(0.95)$ & $\tau_{98, y}(0.95)$ \\
\hline units & & & {$[\mathrm{keV}]$} & {$[\mathrm{MW}]$} & {$[\mathrm{MW}]$} & {$[\mathrm{s}]$} & {$[\mathrm{s}]$} \\
\hline 50000G07 & 0.29 & 1.30 & 5.4 & 81.7 & 16.2 & 0.89 & 0.68 \\
50000G09 & 0.44 & 1.90 & 5.4 & 169 & 34.2 & 0.81 & 0.56 \\
50000G10 & 0.58 & 2.52 & 5.4 & 287 & 58.0 & 0.73 & 0.47 \\
50000G13 & 0.66 & 2.83 & 5.4 & 355 & 72.0 & 0.67 & 0.42 \\
50000G14 & 0.66 & 2.46 & 4.5 & 285 & 56.0 & 0.71 & 0.50 \\
50000G15 & 0.66 & 1.75 & 2.72 & 152 & 30.0 & 0.83 & 0.74 \\
50000G18 & 0.66 & 1.40 & 2.06 & 94.5 & 18.5 & 0.94 & 0.94 \\
50000G17 & 0.66 & 0.98 & 1.35 & 36 & 7.2 & 0.90 & 1.20 \\
& & & & & & & \\
\hline \hline
\end{tabular}

Table 1. Summary of FIRE plasma parameters at a steady state time (26.5 s).

\begin{tabular}{||lcccccc||}
\hline \hline TRANSP run ID & $T_{\text {ped }}$ & $D_{\text {ash }}$ & $V_{\text {ash }}$ & $\int d V n_{\text {ash }}$ & $\beta_{n}$ & $P_{d t}$ \\
\hline units & {$[\mathrm{keV}]$} & {$\left[\mathrm{m}^{2} / \mathrm{s}\right]$} & {$[\mathrm{m} / \mathrm{s}]$} & {$\left[10^{20}\right.$} & & {$[\mathrm{MW}]$} \\
\hline 03000G03 & & & & & & \\
03000G04 & 3.6 & 0.8 & 0 & 1.8 & 1.54 & 332 \\
03000G05 & 3.9 & 0.8 & -0.1 & 4.5 & 1.51 & 313 \\
03000G06 & 5.1 & 0.8 & 0 & 2.4 & 1.86 & 451 \\
03000G08 & 5.1 & 0.8 & -0.1 & 6.2 & 1.66 & 425 \\
& 5.1 & 0.5 & 0 & 2.44 & 1.85 & 442 \\
\hline \hline
\end{tabular}

Table 2. Summary of ITER-FEAT plasma parameters at $300 \mathrm{~s}$. 
References

[1] D. Meade et al., presented at the Eighteenth International Conference on Plasma Physics and Controlled Fusion Research, Sorrento, Italy, 4-10 October 2000. The web site for FIRE is http://fire.pppl.gov.

[2] D.J. Campbell, Phys. Plasmas 8 (2001) 2041.

[3] R.E. Waltz, G.M. Staebler, W. Dorland, G.W. Hammett, et al., Phys. Plasmas 4 (1997) 2482.

[4] R.V. Budny, M.G. Bell, A.C. Janos, et al., Nucl. Fusion 35 (1995) 1497, and references therein.

[5] S.C. Jardin, N. Pomphrey, and J. Delucia, J. Comput. Phys., 46 (1996) 481.

[6] R.J. Goldston, D.C. McCune, H.H. Towner, S.L. Davis, et al., J. Comput. Phys. 43 (1981) 61.

[7] M. Evrard, J. Ongena, and D. van Eester, "Improved Dielectric Tensor in the ICRH module of TRANSP", in AIP Conference Proceedings 335, Radio-Frequency Power in Plasmas, 11th topical conference, Palm Springs (1995) 235.

[8] R.V. Budny, "Fusion Alpha Parameters in Tokamaks with High DT Fusion Rates",PPPL Report 3674-revised (2002), submitted for publication.

[9] R.V. Budny, "Simulations of the neutral-beam-induced rotation, radial electric field, and flow shearing rate in next-step burning plasmas", submitted to the 2002 Snowmass conference. [10] W. Houlberg, K. Shang, S. Hirshman, and M. Zarnstorff, Phys. Plasmas 4 (1997) 3230. 


\section{Figure Captions}

Fig. 1 - Evolution of the heating powers in a FIRE plasma.

Fig. 2 - Evolution of the assumed total current and computed $I_{b o o t}$ in a FIRE plasma.

Fig. 3 - Profile of $q_{M H D}$ for one of the FIRE plasmas.

Fig. 4 - Evolution of the assumed central density in a FIRE plasma.

Fig. 5 - Density profiles at a flattop time.

Fig. 6 - Evolution of $q_{M H D}$ with various Greenwald fractions.

Fig. 7 - Evolution of central and pedestal temperatures for one of the FIRE plasmas.

Fig. 8 - Scaling of $T_{i}$ with Greenwald fraction.

Fig. 9 - Scaling of dt fusion power with Greenwald fraction in FIRE plasma with $T_{\text {ped }}=\mathbf{5 . 4} \mathrm{KeV}$.

Fig.10 - Scaling of with the pedestal Temperature.

Fig.11 - Scaling of $T_{e}$ with the pedestal Temperature.

Fig.12 - Scaling of dt fusion power with $T_{p e d}$.

Fig.13 - Heating powers for ITER-FEAT with $T_{p e d}=5.1 \mathrm{keV}$.

Fig.14 - Temperature profiles from two simulations of ITER-FEAT with different pedestal temperatures.

Fig. 15 - Helium ash profiles in ITER-FEAT before and after a sawtooth crash. 
Heating powers in a FIRE H-mode plasma

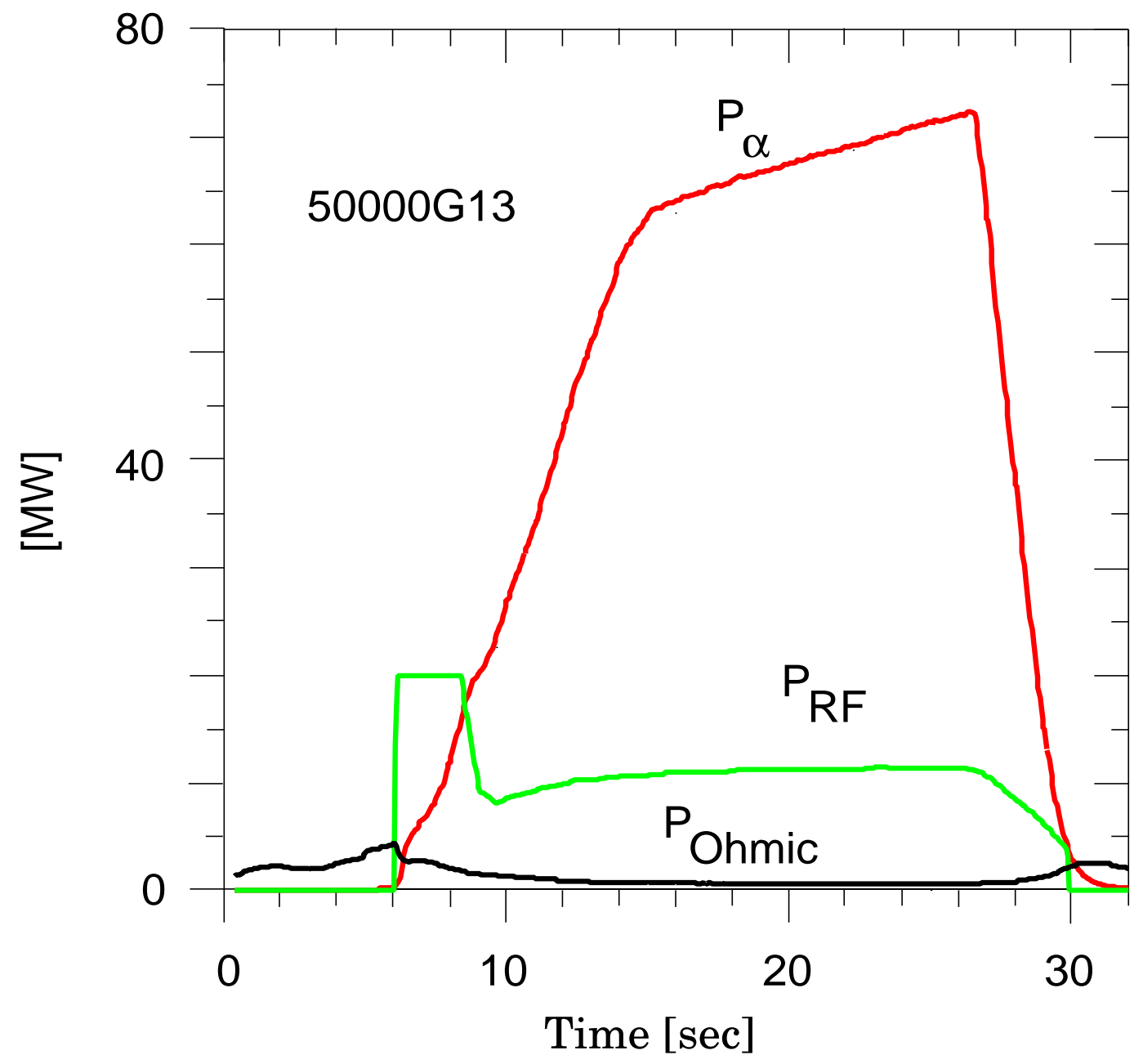

Figure 1. Evolution of the heating powers in a FIRE plasma. 


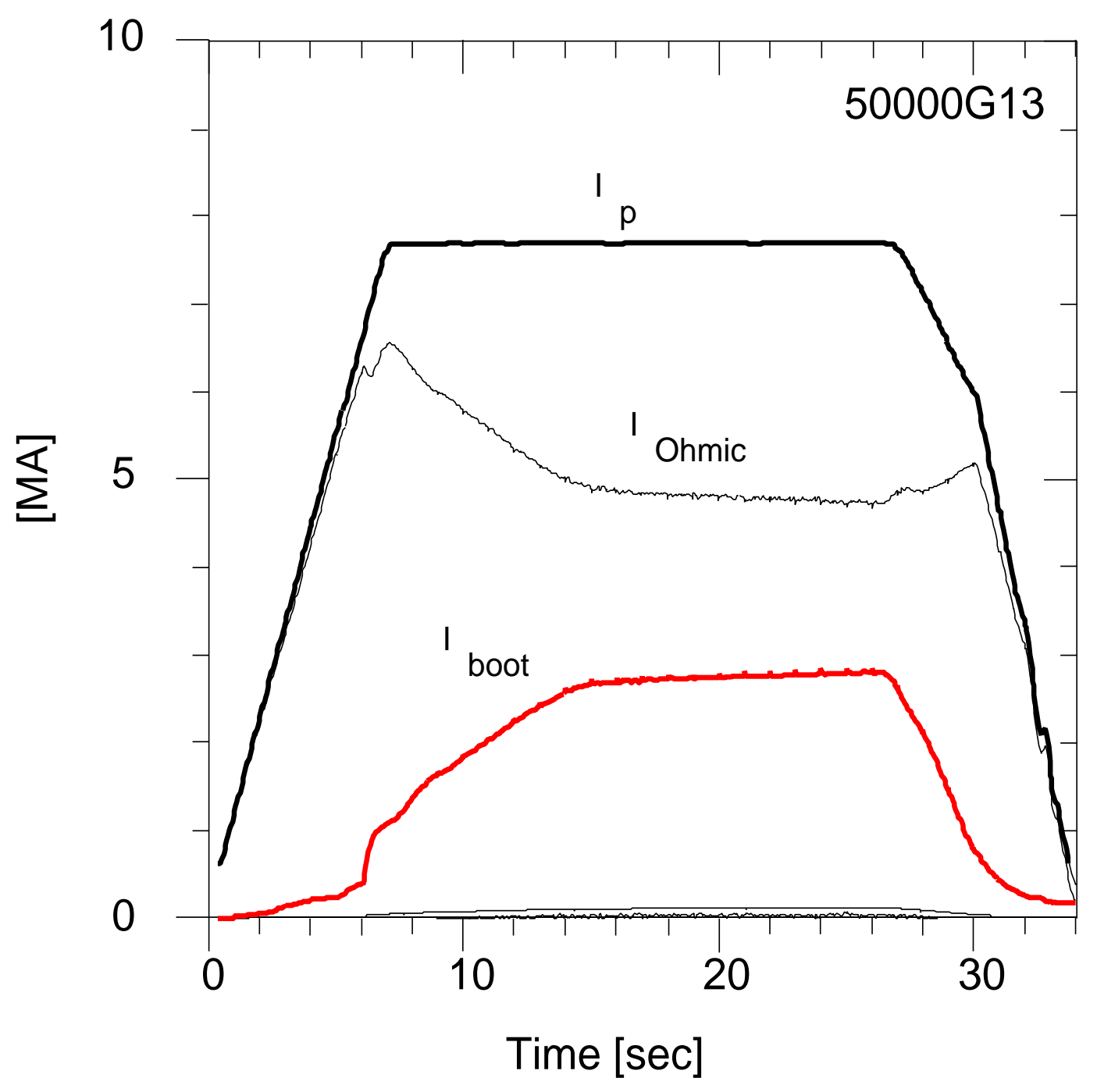

Figure 2. Evolution of the assumed total current and computed $I_{\text {boot }}$ in a FIRE plasma. 


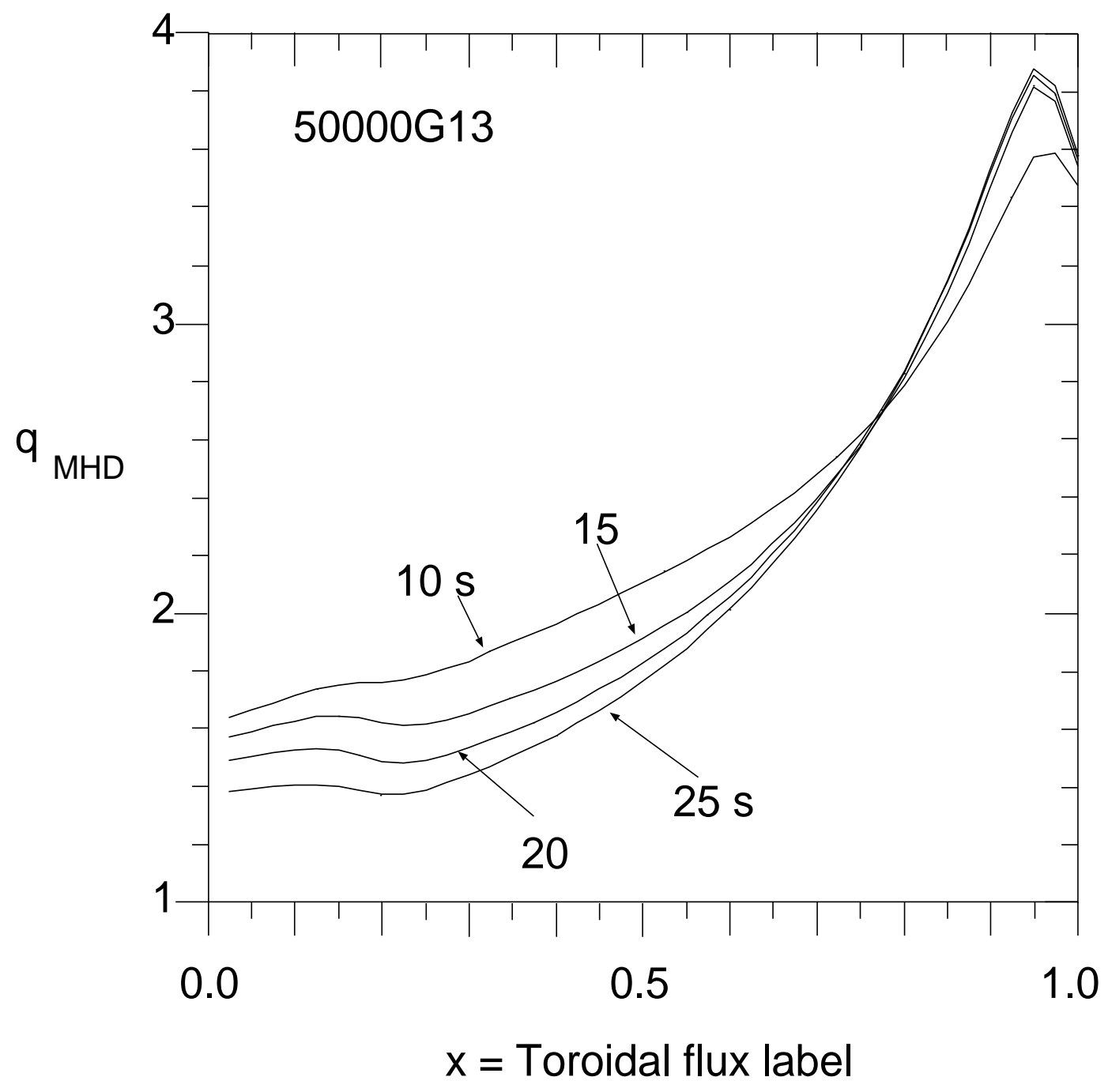

Figure 3. Profile of $q_{M H D}$ for one of the FIRE plasmas. 


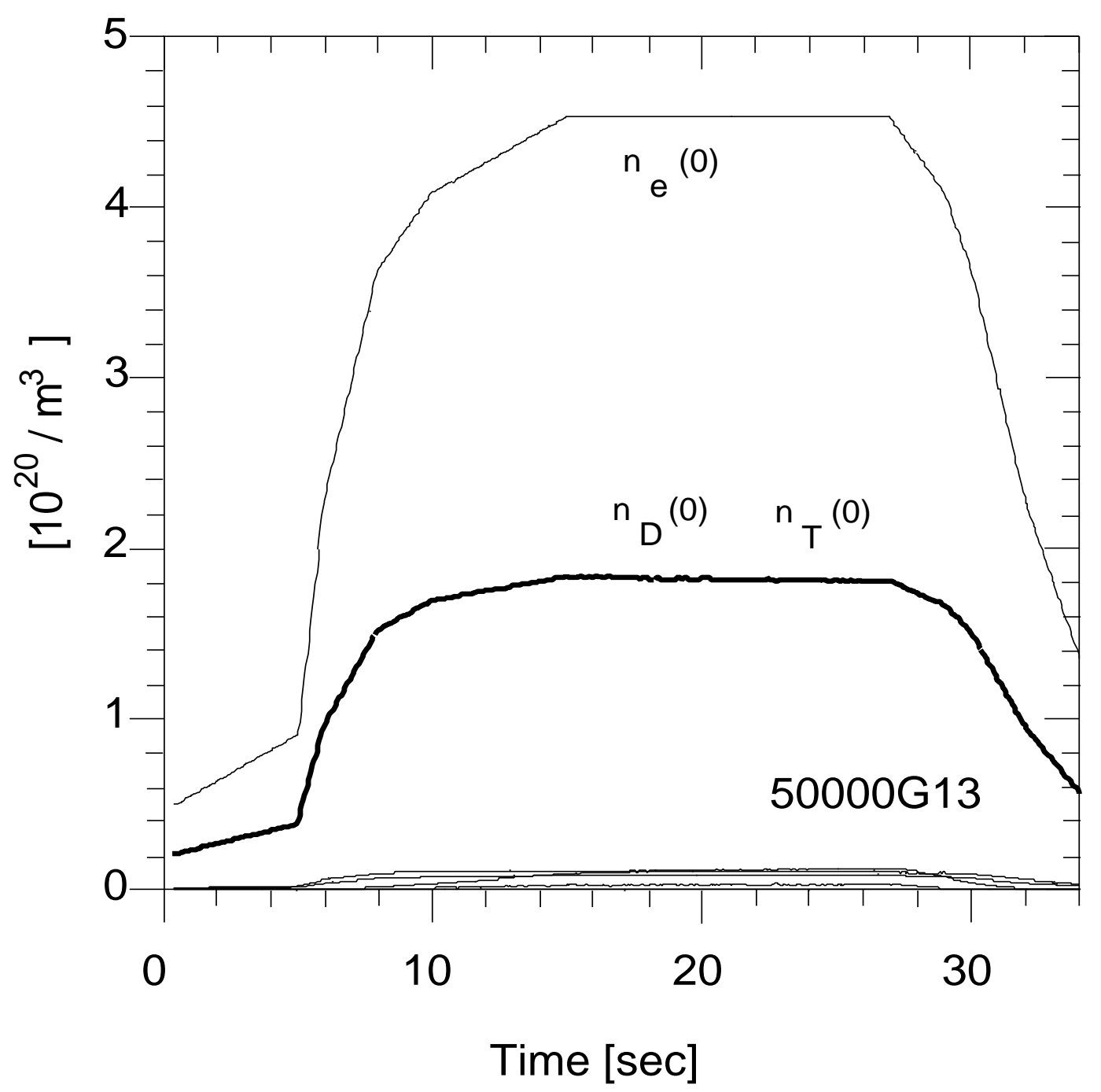

Figure 4. Evolution of the assumed central density in a FIRE plasma. 


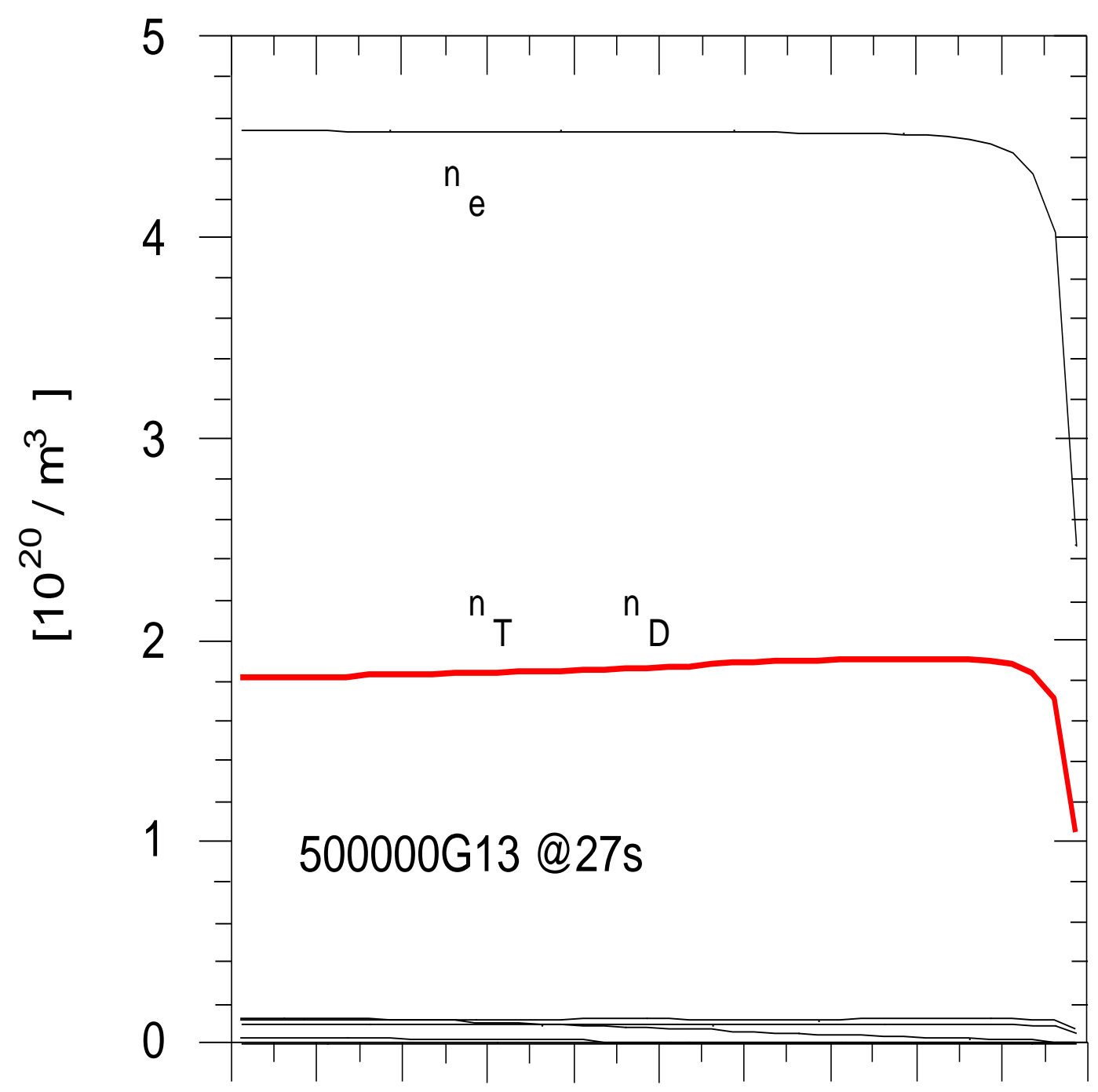

Figure 5. Density profiles at a flattop time. 


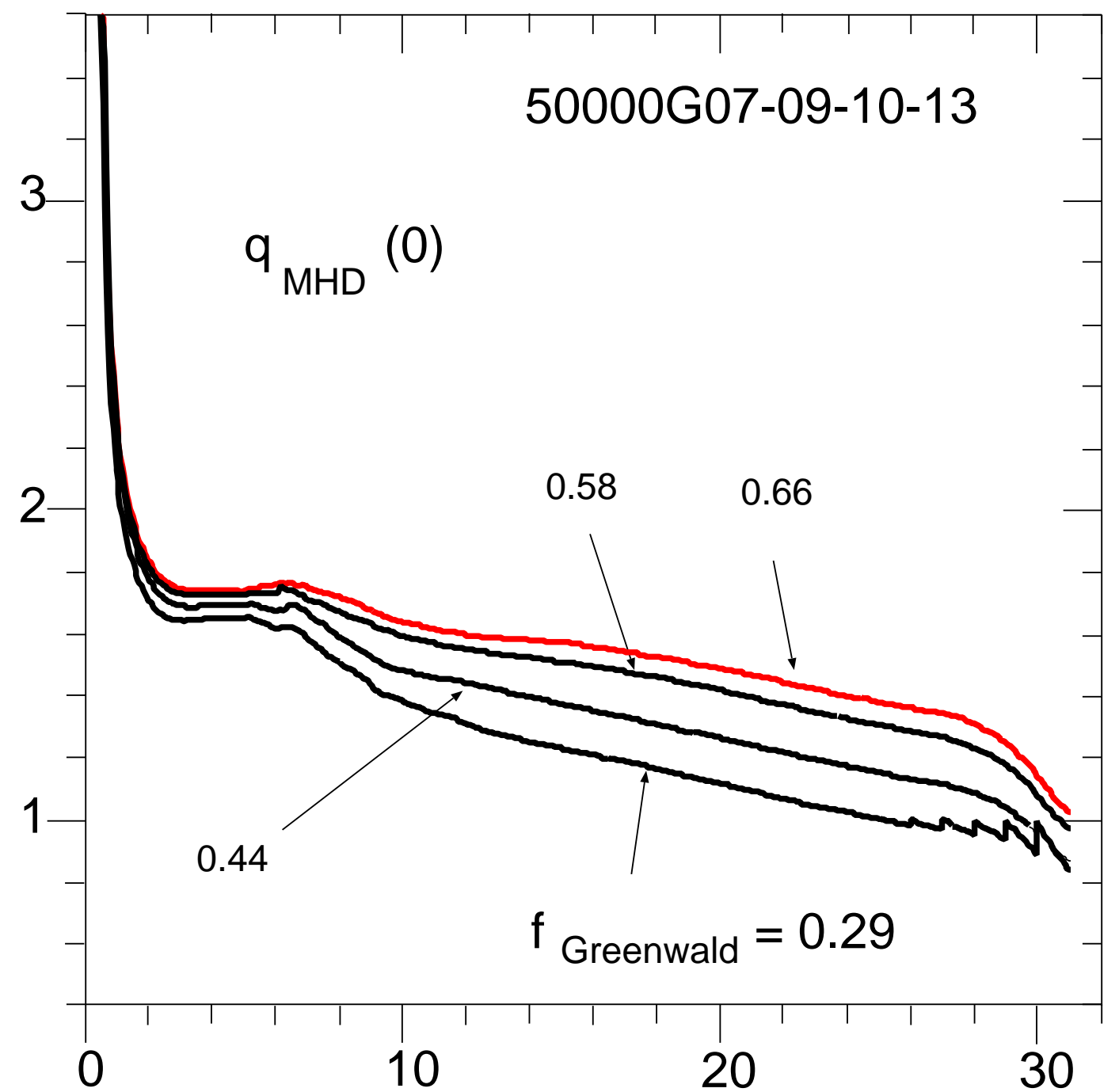

Figure 6. Evolution of $q_{M H D}$ with various Greenwald fractions. 


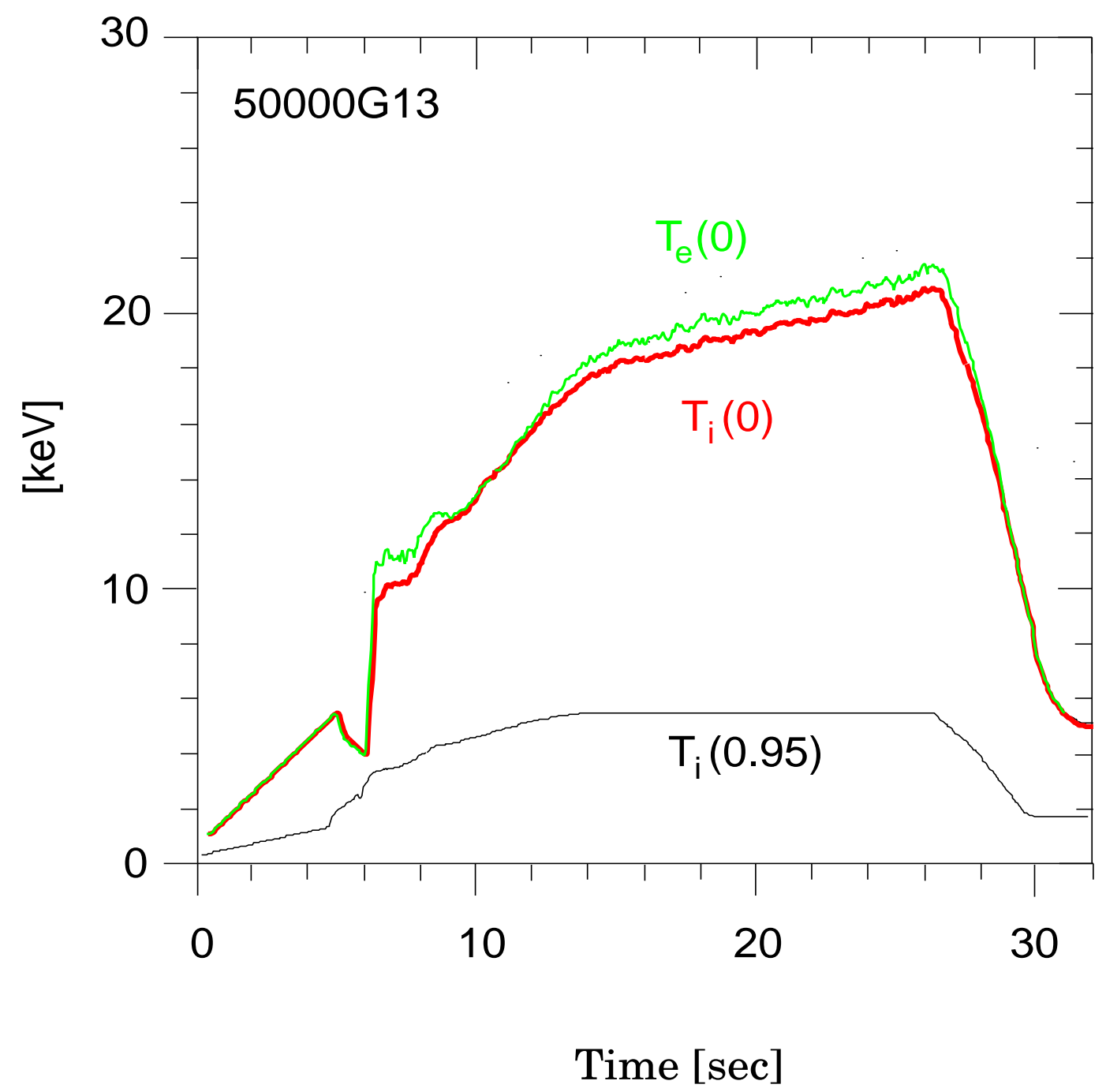

Figure 7. Evolution of central and pedestal temperatures for one of the FIRE plasmas. 


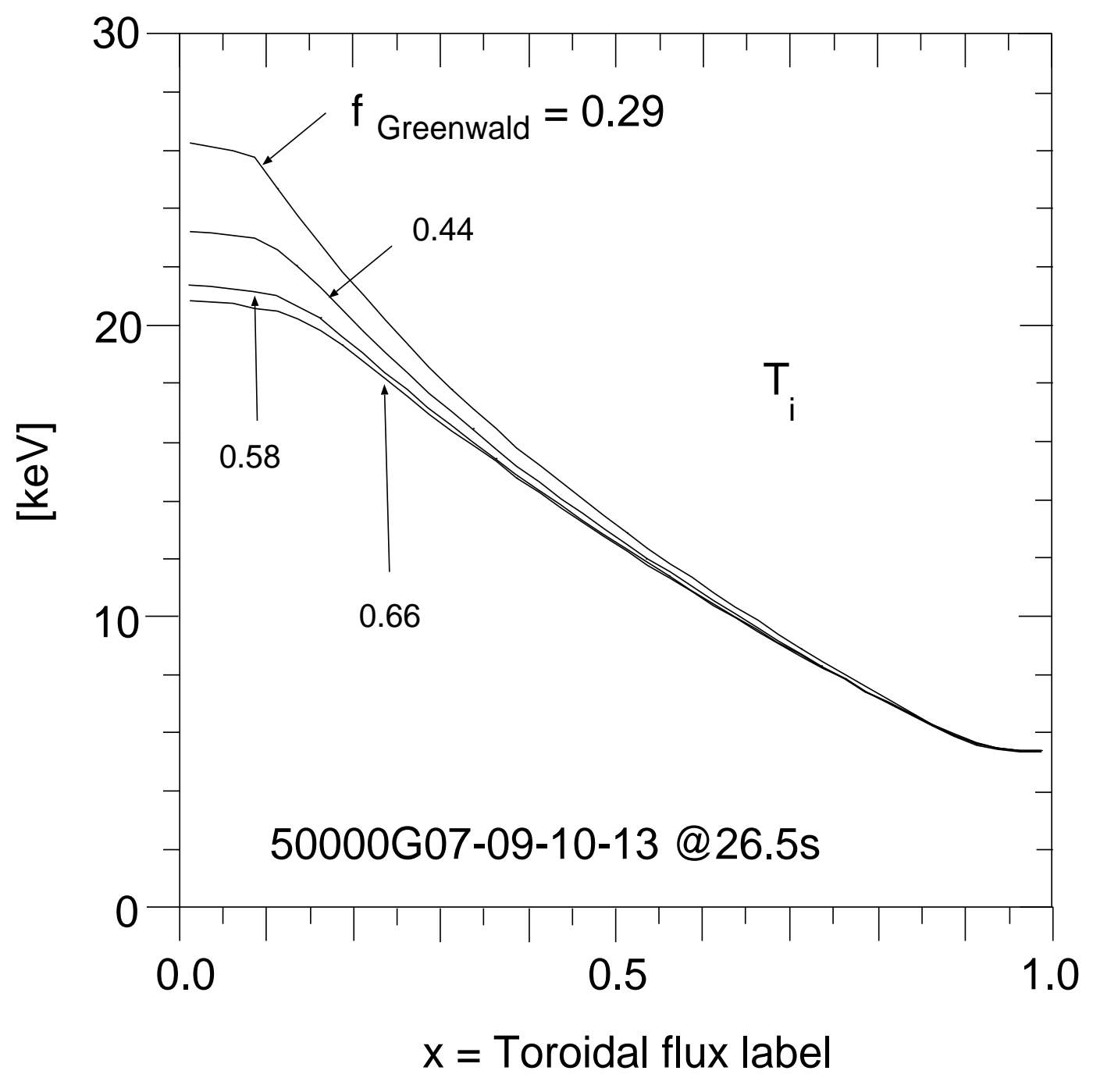

Figure 8. Scaling of $T_{i}$ with Greenwald fraction. 
TRANSP-GFL23 simulations of FIRE

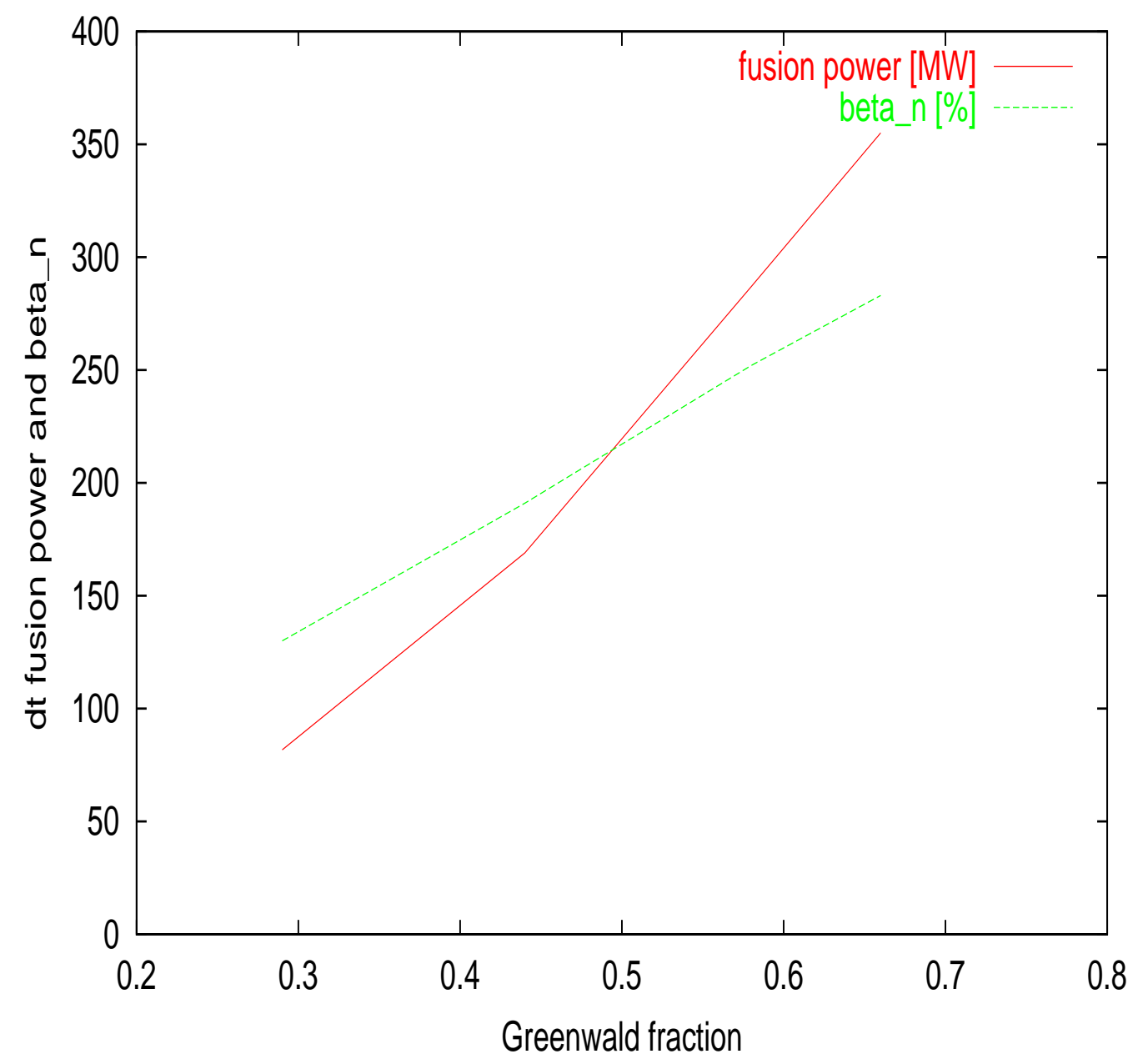

Figure 9. Scaling of dt fusion power with Greenwald fraction in FIRE plasma with $T_{\text {ped }}=5.4 \mathrm{KeV}$. 


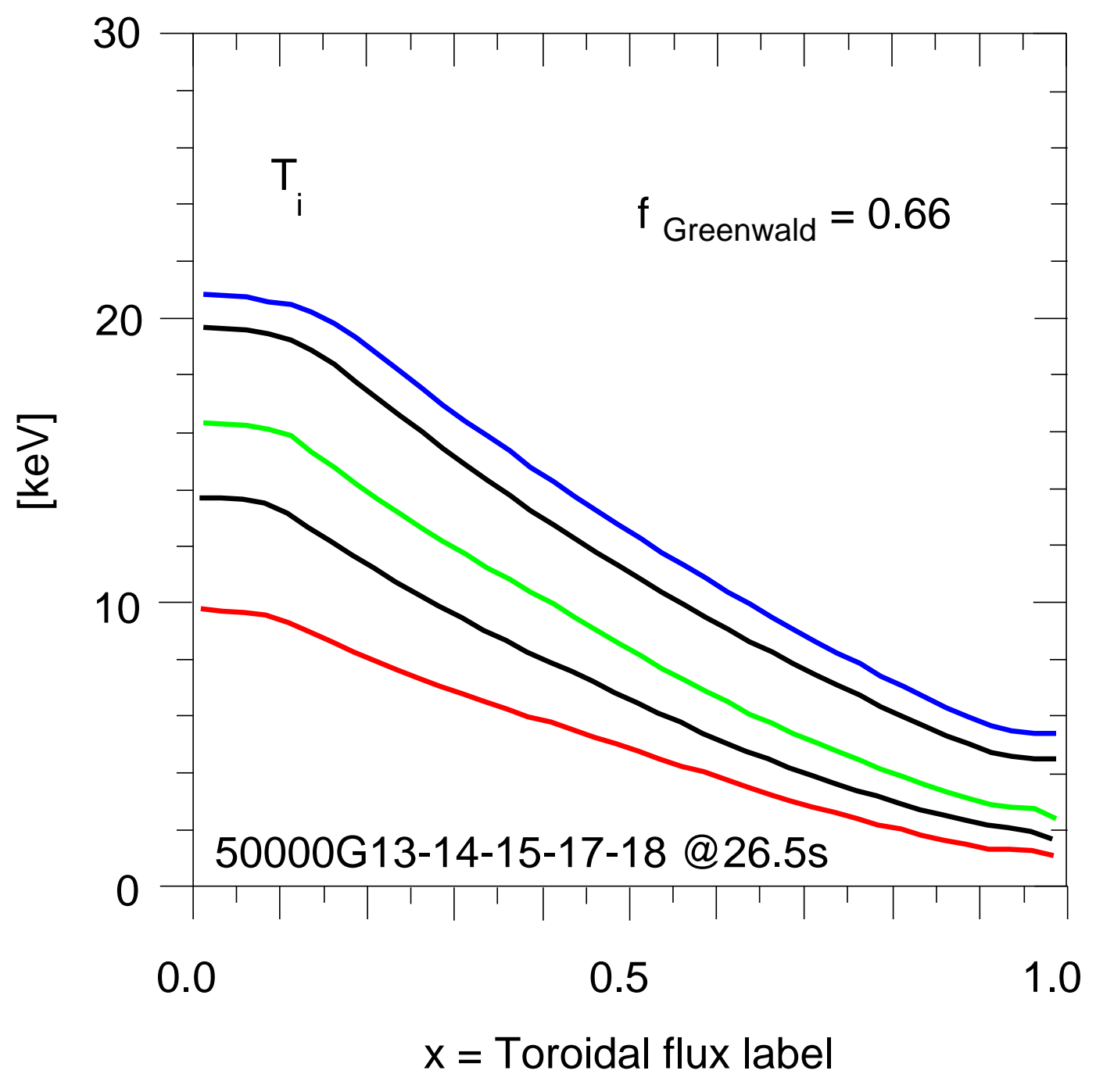

Figure 10. Scaling of with the pedestal Temperature. 


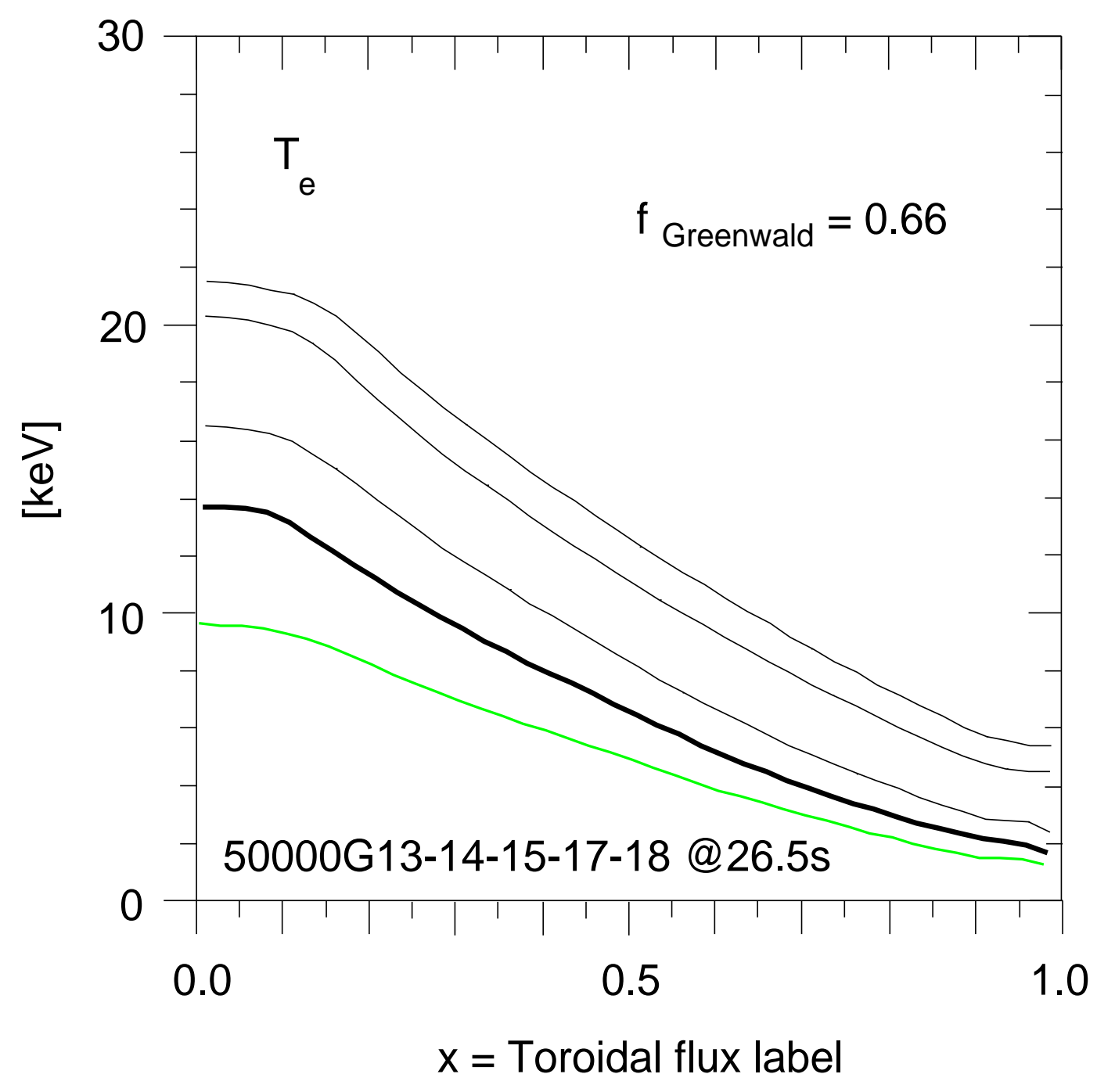

Figure 11. Scaling of $T_{e}$ with the pedestal Temperature. 
TRANSP-GFL23 simulations of FIRE

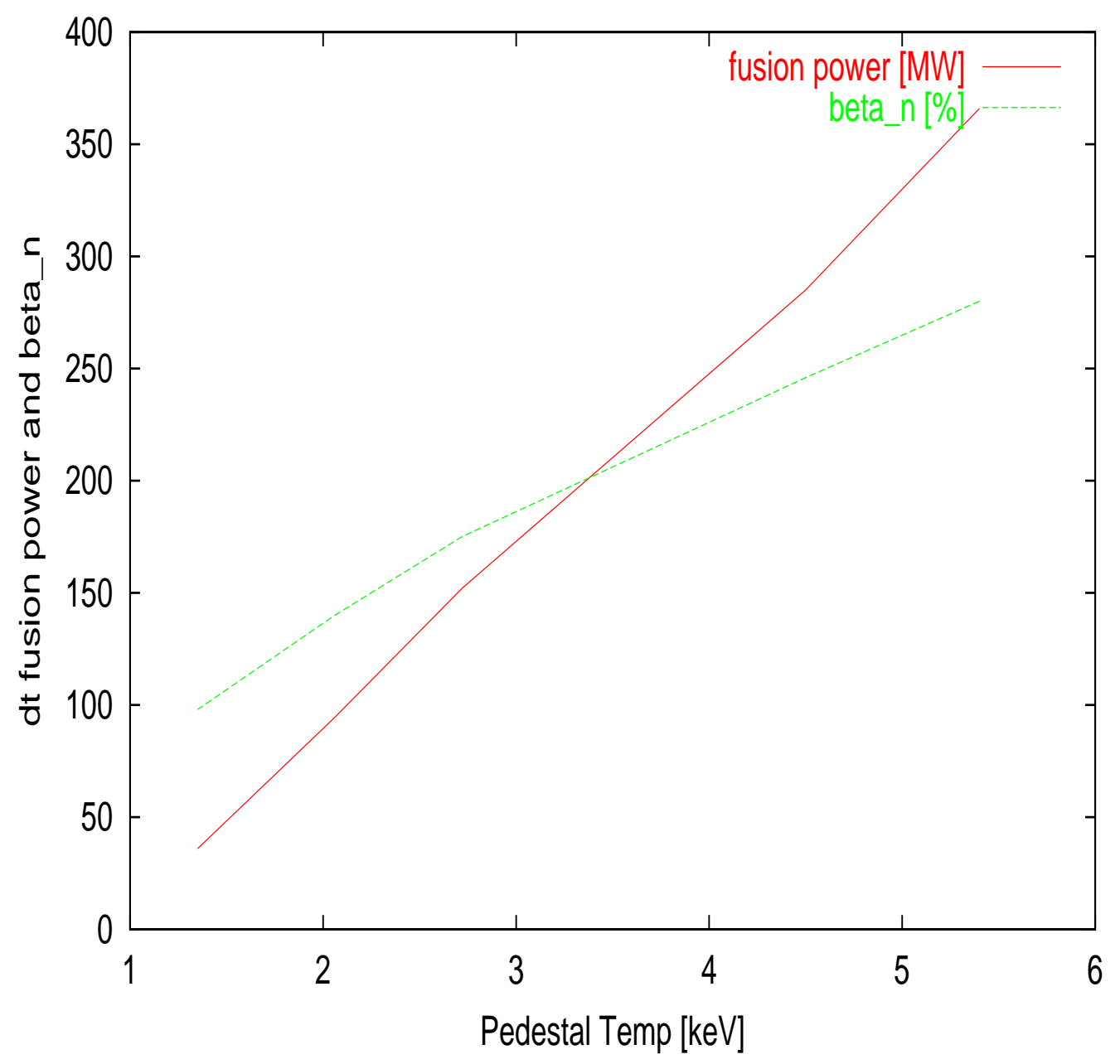

Figure 12. Scaling of dt fusion power with $T_{\text {ped }}$. 


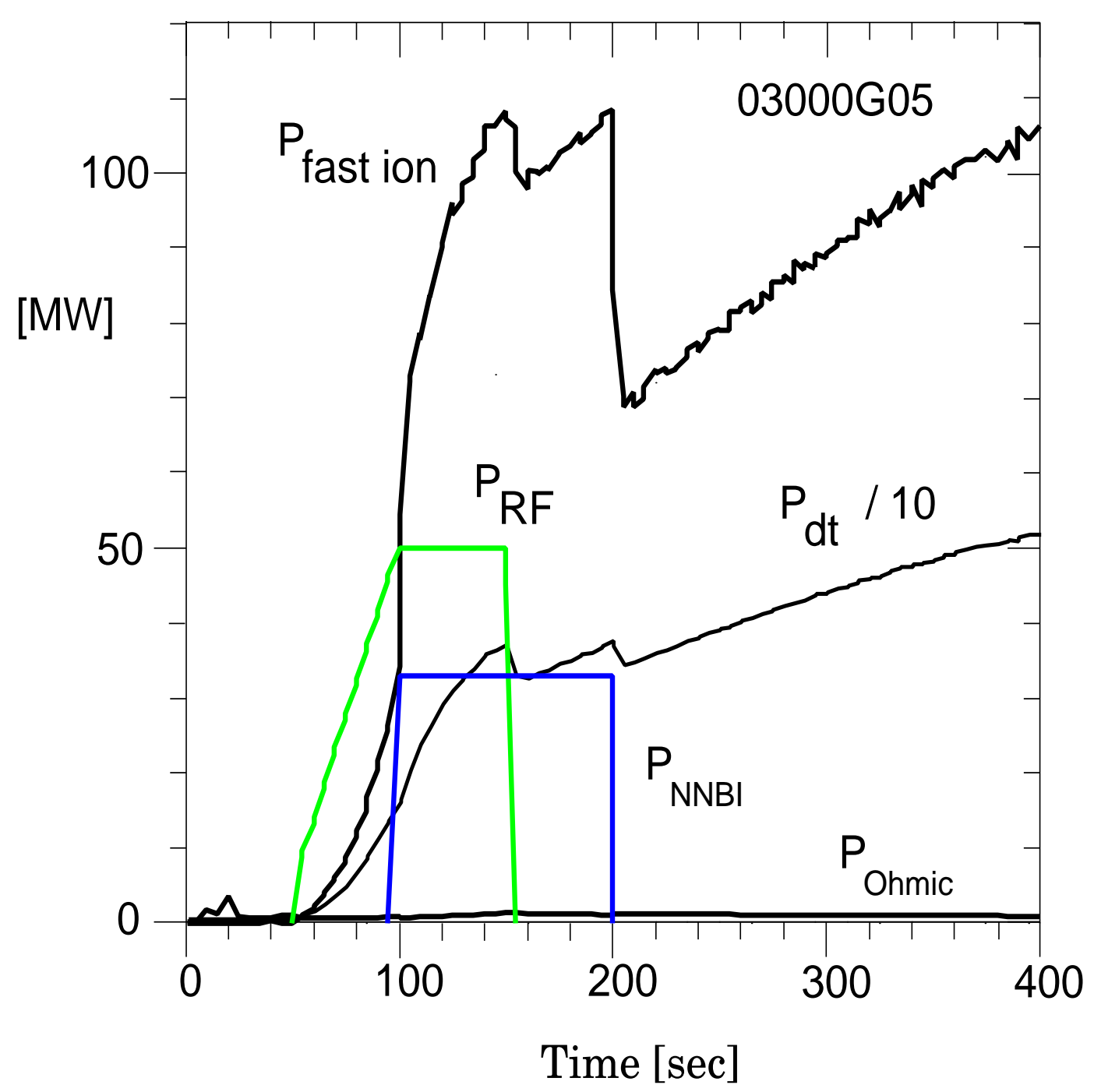

Figure 13. Heating powers for ITER-FEAT with $T_{p e d}=5.1 \mathrm{keV}$. 


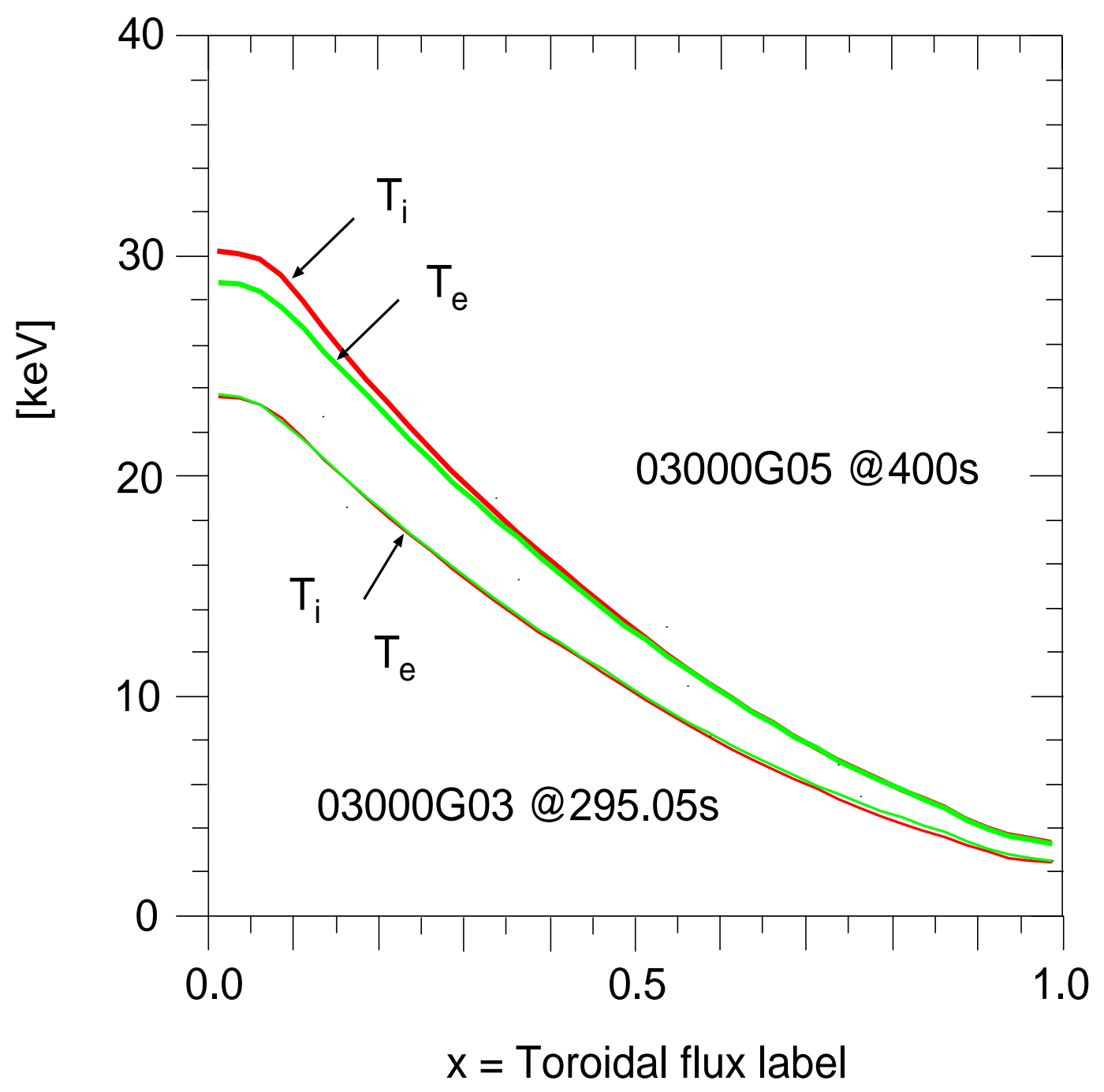

Figure 14. Temperature profiles from two simulations of ITER-FEAT with different pedestal temperatures. 


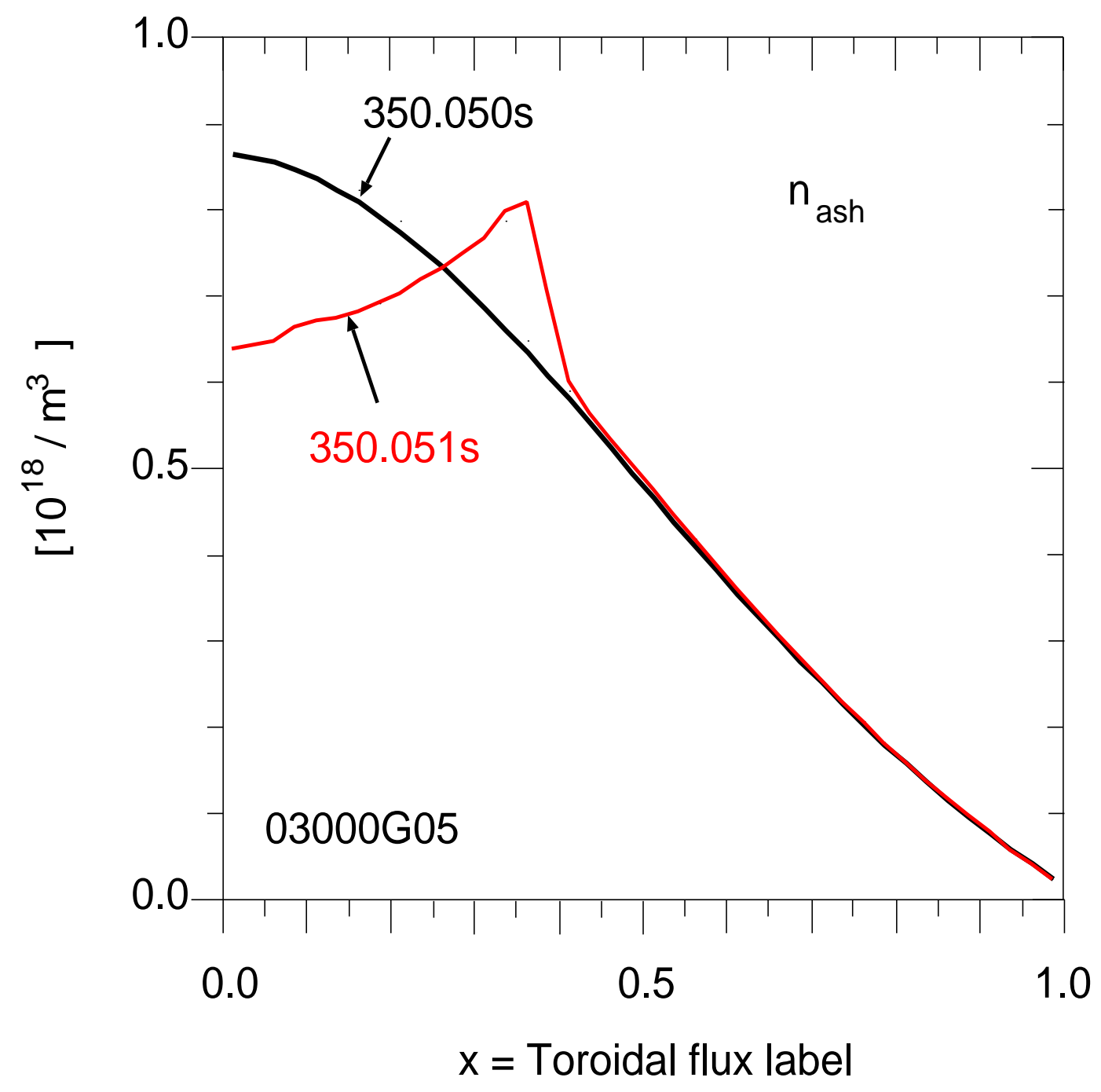

Figure 15. Helium ash profiles in ITER-FEAT before and after a sawtooth crash. 


\section{External Distribution}

Plasma Research Laboratory, Australian National University, Australia

Professor I.R. J ones, Flinders University, Australia

Professor J oão Canalle, Instituto de Fisica DEQ/IF - UERJ , Brazil

Mr. Gerson O. Ludwig, Instituto Nacional de Pesquisas, Brazil

Dr. P.H. Sakanaka, Instituto Fisica, Brazil

The Librarian, Culham Laboratory, England

Library, R61, Rutherford Appleton Laboratory, England

Mrs. S.A. Hutchinson, JET Library, England

Professor M.N. Bussac, Ecole Polytechnique, France

Librarian, Max-Planck-Institut für Plasmaphysik, Germany

J olan Moldvai, Reports Library, MTA KFKI-ATKI, Hungary

Dr. P. Kaw, Institute for Plasma Research, India

Ms. P.J . Pathak, Librarian, Insitute for Plasma Research, India

Ms. Clelia De Palo, Associazione EURATOM-ENEA, I taly

Dr. G. Grosso, Instituto di Fisica del Plasma, Italy

Librarian, Naka Fusion Research Establishment, J AERI, J apan

Library, Plasma Physics Laboratory, Kyoto University, J apan

Research Information Center, National Institute for Fusion Science, J apan

Dr. O. Mitarai, Kyushu Tokai University, J apan

Library, Academia Sinica, Institute of Plasma Physics, People's Republic of China

Shih-Tung Tsai, Institute of Physics, Chinese Academy of Sciences, People's Republic of China

Dr. S. Mirnov, TRINITI, Troitsk, Russian Federation, Russia

Dr. V.S. Strelkov, Kurchatov Institute, Russian Federation, Russia

Professor Peter Lukac, Katedra Fyziky Plazmy MFF UK, Mlynska dolina F-2, Komenskeho Univerzita, SK-842 15 Bratislava, Slovakia

Dr. G.S. Lee, Korea Basic Science Institute, South Korea

Mr. Dennis Bruggink, Fusion Library, University of Wisconsin, USA

Institute for Plasma Research, University of Maryland, USA

Librarian, Fusion Energy Division, Oak Ridge National Laboratory, USA

Librarian, Institute of Fusion Studies, University of Texas, USA

Librarian, Magnetic Fusion Program, Lawrence Livermore National Laboratory, USA

Library, General Atomics, USA

Plasma Physics Group, Fusion Energy Research Program, University of California at San Diego, USA

Plasma Physics Library, Columbia University, USA

Alkesh Punjabi, Center for Fusion Research and Training, Hampton University, USA

Dr. W.M. Stacey, Fusion Research Center, Georgia Institute of Technology, USA

Dr. J ohn Willis, U.S. Department of Energy, Office of Fusion Energy Sciences, USA

Mr. Paul H. Wright, Indianapolis, Indiana, USA 
The Princeton Plasma Physics Laboratory is operated by Princeton University under contract with the U.S. Department of Energy.

\author{
Information Services \\ Princeton Plasma Physics Laboratory \\ P.O. Box 451 \\ Princeton, NJ 08543
}

Phone: 609-243-2750

Fax: 609-243-2751

e-mail: pppl_info@pppl.gov

Internet Address: http://www.pppl.gov 